\title{
LETTERS
}

\section{Drug importation into the United States: impact on Canada}

I write in support of the recent commentary by Nigel Rawson and Louise Binder. ${ }^{1}$ My recent research examining the effect of US drug importation on Canada supports this commentary.

The focus of the proposed bill in the US (i.e., the Affordable and Safe Prescription Drug Importation Act) is on personal importation of drugs from Canada; however, the bill would legalize commercial drug importation by US pharmacies, clinics, hospitals and wholesalers. Rawson and Binder stated, "[drug] shortages would increase in Canada and cause substantial distress to Canadians." ${ }^{1}$ In my opinion, the impact on Canada will be more than distressing, it will be devastating for Canada.

A decade ago, I concluded that Canada does not have the drug supply and cannot afford to become the drugstore for the US. ${ }^{2}$ I updated the projection models, and I again concluded that Canada's drug supply is inadequate to meet US demands (http://safedr.ug/2017_ casupply). If just $20 \%$ of Americans were to import prescription drugs from Canada, the 2015 Canadian prescription drug supply would be exhausted in 151 days. If a $20 \%$ surplus is added to that drug supply, then it would last 183 days or about six months. Excluding generic drugs, the model projects a 201-day supply for patented drugs. Obviously, drugs with a high demand will be exhausted sooner, which would cause shortages for Canada. It is unlikely that pharmaceutical firms in the US will increase their supplies to Canada because of the arbitrage.

Canada needs to proceed cautiously about drug importation into the US. US drug importation from Canada will have devastating effects on Canada.

\section{Marv D. Shepherd PhD}

Retired, Professor Emeritus, University of Texas at Austin, Austin, Tex.

- Cite as: CMAJ 2017 September 25;189:

E1216. doi: 10.1503/cmaj.733387

\section{References}

1. Rawson NSB, Binder L. Importation of drugs into the United States from Canada. CMAJ 2017;189:E817-8.

2. The effect of US pharmaceutical drug importation on the Canadian pharmaceutical supply. Can Pharm J 2010;143:226-33.

Competing interests: Marv Shepherd is President, Board of Directors, Partnership for Safe Medicine. 